\title{
Framework for open insurance strategy: insights from a European study
}

\author{
Willem Standaert ${ }^{1}$ (D) Steve Muylle ${ }^{2}$
}

Received: 14 June 2021 / Accepted: 6 January 2022 / Published online: 2 February 2022

(C) The Geneva Association 2022

\begin{abstract}
While some consider open insurance to be a buzzword with more hype than substance, the underlying trend of open finance stimulates insurers to use digital technology to exchange data with third parties to realise process efficiencies and develop new products and channels. Based on a literature review and 30 interviews with industry experts in Europe, we define open insurance, identify its key drivers, and discuss the dimensions and performance impact of open insurance strategy. The combined insights can help executives develop a better understanding of open insurance and formulate an open insurance strategy that provides performance benefits to them, customers, and third parties.
\end{abstract}

Keywords Open insurance · Digitalisation · Data-enabled services · InsurTech · Big Tech $\cdot$ Regulation

\section{Introduction}

Back in 2002, in a debate among senior executives of insurance companies, the $\mathrm{CEO}$ of the former Belgian insurer Fortis (now Ageas) noted that the "traditional view of looking at our business as a closed and fully integrated system has become obsolete" (van Rossum et al. 2002, p. 90). The then CEO of French insurer AXA added: "Because consumers will demand a broad range of products from several insurers from their financial services provider, insurers will need to adopt an open architecture to leverage access to customers" (p. 93). While these senior executives envisioned the advent of what is now called 'open insurance' 20 years ago, many insurers have still not adopted such an approach. What is more, in its 2021 Digital Insurance Hype Cycle, Gartner positions open insurance-related concepts and

Willem Standaert

willem.standaert@uliege.be

1 HEC Liège - Management School of the University of Liège, Rue Louvrex 14, 4000 Liège, Belgium

2 Vlerick Business School \& Ghent University, Ghent, Belgium 
technologies such as 'Insurance as a service' and 'Open Application Programming Interfaces' in the 'Innovation Trigger' phase, expecting mainstream adoption to potentially take another five years. ${ }^{1}$

At the same time, open insurance can be viewed as more than a hype and part of a larger trend in financial services, which is referred to as 'open finance'. Recent developments reveal that the financial services industry is transforming from 'walled garden' environments and institutionalised opacity to practices of openness and transparency (Gozman et al. 2018; O'Leary et al. 2021). This transformation is largely driven by the regulator who seeks to level the playing field and stimulate competition (Zetzsche et al. 2019). The European Commission is expected to implement a broad framework for data exchange via application programming interfaces (APIs) by mid-2022 in financial services and beyond (e.g. social media, e-commerce sites, public entities, utilities, telecommunications and retail) (Morvan 2021; EIOPA 2021). Other stakeholders are also contributing to the development of open finance: both corporate customers and individual consumers are increasingly expecting financial service providers to open their data for enhanced convenience and better experiences (Holland et al. 2020). Likewise, Big Tech, FinTech and InsurTech players are embracing this trend through innovative services and offerings (Eling and Lehmann 2018; Lanfranchi and Grassi 2021). Moreover, industry experts consider the COVID-19 pandemic as a potential catalyst for further improving customer experiences and personalisation through open finance. ${ }^{2}$

Until now, the open finance trend has manifested itself most notably and visibly in the banking industry in Europe (Morvan 2021). 'Open banking' was set in motion in September 2019 by the regulatory framework of the second Payments Services Directive (PSD2), administered by the European Commission and the European Banking Authority, ${ }^{3}$ which requires financial services firms to enable a secure data exchange with licensed third parties for payment accounts. In addition, open banking holds strong potential for new types of offerings (e.g. 'beyond banking'), goto-market approaches (e.g. banking-as-a-service) and customer experiences (e.g. aggregation of accounts and comparison of providers) (Standaert et al. 2020). In terms of technologies, open banking is essentially enabled by APIs (Zachariadis and Ozcan 2017; Gozman et al. 2018), which support data exchange and communication between two software programmes (for instance of a bank and a FinTech). Indeed, in Gartner's 2019 Open Banking Hype Cycle, 'Private APIs' had already reached the 'Plateau of Productivity' phase and 'Public APIs' were about to enter the 'Slope of

\footnotetext{
${ }^{1}$ https://www.gartner.com/en/documents/4003191-hype-cycle-for-digital-life-and-p-c-insurance-2021.

${ }^{2}$ For instance, see https://www.insurancebusinessmag.com/asia/news/breaking-news/how-can-insur ers-improve-the-customer-experience-postcovid19-254921.aspx (accessed on 10 June 2021) and https:// www.postonline.co.uk/claims/7656121/spotlight-open-insurance-restoring-confidence-and-seizing-oppor tunities-post-covid-19 (accessed on 10 June 2021).

${ }^{3}$ The European Banking Authority develops directives to enhance secure data exchanges, as part of its mission to implement harmonised European regulations.
} 
Enlightenment', which implies they had already passed the 'Peak of Inflated Expectations' and the 'Trough of Disillusionment'.

Although there is synergy and overlap among firms in the financial services industry in terms of offering banking and insurance products, the insurance context is different from that of banking in several ways (Schiro 2006; Trichet 2005). First, there is no regulation related to data exchange for insurance products (yet) and as a consequence, there is a lack of standardisation and interoperability (EIOPA 2021). Second, there is a higher variety and ever increasing range of types of insurance products, as there are potentially as many products as there are risks in society (Gollier 1997). Third, insurance is 'data rich' (even more so than banking), and it is a product with (a variety of) data at its foundation (Mulhall et al. 2017). The data can also include very personal and sensitive health data (Maas et al. 2008), which complicates data handling. Finally, customers generally have few interactions with insurance products, beyond their initiation and when filing a claim, and hence have infrequent touch points with insurance providers (Järvinen et al. 2003). For all these reasons, a study focusing specifically on open insurance is warranted.

In addition to defining 'open insurance', our study aims to address the following research questions:

1. What are the key drivers of open insurance?

2. What are the different dimensions to consider when developing open insurance strategy (i.e. what can be opened and what levels of openness can be distinguished?)

3. What is the performance impact of open insurance strategy?

To answer these questions, we have developed an interview guide based on the literature, which we then used to interview 30 subject matter experts from different types of insurance organisations in Europe. We then developed a framework for open insurance strategy by combining the insights from the literature review and expert study.

This paper is structured as follows. In the "Literature review" section, we review various definitions as well as prior work on digitalisation in insurance related to data, products, distribution channels, and performance impact. Then, we discuss our qualitative research method and address potential validity and reliability issues in the "Research approach" section. We present and discuss our findings in the next four sections: "Definition of open insurance", "Drivers of open insurance", "Open insurance framework: dimensions and levels of openness" and "Impact of open insurance strategy". We conclude the paper in the final section.

\footnotetext{
${ }^{4}$ https://www.gartner.com/en/documents/3970082/hype-cycle-for-open-banking-2019; private APIs are developed and hosted in-house, whereas public APIs grant outside access to internal applications.
} 


\section{Literature review}

We start this section by reviewing prior definitions of 'open finance', 'open banking', and 'open insurance' from the academic and practitioner literatures. Based on these definitions and a brief review of open banking research, we provide our own definition of open insurance and focus our literature review on three key dimensions of open insurance: data, products, and ecosystems, and their digitalisation. We conclude the literature review with a discussion of the impact of digitalisation in insurance.

\section{Prior definitions}

As there is limited academic research to date that defines open finance, open banking, or open insurance (Gozman et al. 2018; O'Leary et al. 2021), we review the commonly-used descriptions and definitions below.

Open finance has been described by the UK Financial Conduct Authority as being "based on the principle that the data supplied by and created on behalf of financial services customers are owned and controlled by those customers. Re-use of these data by other providers takes place in a safe and ethical environment with informed consumer consent. This would mean that a financial services customer who consents to a Third Party Provider accessing their financial data, could be offered tailored products and services as a result" (Financial Conduct Authority 2021, p. 13).

As to open banking, O'Leary et al. (2021) provide an overview of dimensions used in definitions by practitioners. They found that data sharing was mentioned most frequently, followed by (licensed) third parties, security, new products and services, customer data ownership (and consent), increased customer value, and (API) data standards. Regulators, on the other hand, referred most often to increased competition in their definitions of open banking. The authors also provide a synthesised definition (O'Leary et al. 2021, p. 5899): “Open Banking is an initiative which facilitates the secure sharing of account data with licensed third parties through Application Programming Interfaces (APIs), empowering customers with ownership of their own data. The initiative aims to increase competition in retail banking by developing innovative products and services which will bring increased value to customers."

As to open insurance, EIOPA (2021, p. 11) describes it as "covering, accessing and sharing insurance-related personal and non-personal data usually via APIs." Accenture provides a more elaborate description (Holland et al. 2020, p. 4): "Open insurance is the practice of insurers sharing and consuming data and services in order to create more appealing value propositions and new revenue streams. These data and services are exchanged with third parties both within and beyond the insurance industry and are made externally accessible and openly consumable by means of APIs. Where relevant, customers authorize their service 
providers to make their data accessible, in return for which they expect better, more personalized services and experiences."

Synthesising the above descriptions and definitions, it becomes clear that the key attribute of 'open' is the exchange of data, which includes sharing data with customers and third parties, and obtaining data from them. Furthermore, such data exchange enables new forms of data processing, innovative products, and expanding channel ecosystems. To verify the relevance of these dimensions, we reviewed academic research on open banking, which is already somewhat established. We observe that a first focus area has indeed been data and the extent to which their open nature can improve efficiencies and provide value for different stakeholders (O'Leary et al. 2021). In addition, the focus has also been on how banks can open up their product or service scope (Gozman et al. 2018; Standaert et al. 2020), allowing third parties to interact with banking applications to offer complementary capabilities (Ghazawneh and Henfridsson 2013). This is often referred to as a move to 'beyond banking' (Barua et al. 2019). As to the distribution channel in open banking, APIs are considered to be boundary resources (Zachariadis and Ozcan 2017) that enable banks to become ecosystem orchestrators or that put them at risk of being disrupted by Big Tech and FinTech assuming this role (Pousttchi and Gleiss 2019). As orchestrators, banks could include services of third parties. If they instead provide their services on platforms orchestrated by others, they become producers of 'banking-as-a-service' (Gozman et al. 2018; Standaert et al. 2020).

Based on this literature review, we provide the following definition of open insurance: Open insurance is insurance in which proprietary, risk-related, and other data is exchanged with third parties to (1) enhance the efficiency of internal insurance processes, and (2) expand the markets for insurance beyond current products and ecosystems.

In what follows, we review prior work on digitalisation in insurance along the three dimensions identified: data, products, and ecosystems.

\section{Data}

Given the importance of data for insurance-related processes (Pousttchi and Gleiss 2019) and the increasing breadth and depth of (customer) data that becomes available through digital technologies, it is not surprising to see that prior research has focused on this dimension. Several digital technologies can be used to handle and manage data. In the insurance context, Eling and Lehmann (2018) identified various digital technologies for data acquisition and analysis (big data, Internet of Things (IoT), Artificial Intelligence (AI)) and for data storage (blockchain and cloud computing). ${ }^{5}$ Some studies have focused on specific data-related use cases in insurance. For instance, two important applications of big data analytics are fraud

\footnotetext{
5 While also important for data processing, a review of technologies such as blockchain and cloud computing in insurance goes beyond the focus of this paper. We refer the reader to Grima et al. (2020) for a review on blockchain and to Eling and Lehmann (2018) for a review on both blockchain and cloud computing in insurance.
} 
detection (e.g. Tennyson and Salsas-Forn 2002) and customer lifetime value estimation (e.g. Fang et al. 2016). Similarly, prior research has focused on applications of AI (e.g. text mining, natural language processing, image and pattern recognition) and identified their potential impact on different processes related to claim management, underwriting and pricing (Eling et al. 2021).

An important issue related to the use of AI for automated decision making in the insurance industry, which is considered a 'trust management business' (van Rossum 2004,55 ), is the potential lack of transparency into how decisions are made based on data (Dexe et al. 2021). To overcome the issue of black boxed algorithm-based decision making (Rai 2020) and increase customer trust, insurance providers could provide transparency and customer understanding (Dexe et al. 2021). While this is regarded as a potential competitive advantage, insurers are inhibited because of a fear of disclosing sensitive (pricing) information to competitors (Dexe et al. 2021). This issue only becomes more prevalent under General Data Protection Regulation (GDPR) (Dexe et al. 2020). GDPR came into effect in May 2018 and puts individuals at the centre of the data economy by giving them control of their personal data. Some key principles include that people have the right to obtain meaningful information about what type of personal data and logic was used to make decisions; personal data can only be used with an individual's informed consent; and there is a 'right to be forgotten', referring to an individual's right to request to remove personal data. Dexe et al. (2020) examined the responses of insurance companies in Sweden when customers asked about the data used to determine their home insurance premium. They found that the responses varied strongly across insurers in terms of the type of data and logic used for pricing. Some insurers provided an exhaustive list of the types of data used for pricing and explained the logic, while others merely shared some examples, with no explanation concerning the logic (Dexe et al. 2020).

\section{Product}

An important application of digital technology in insurance is product personalisation. For instance, car insurance based on driving distance and behaviour, which is captured through IoT technology (also referred to as telematics in this case) results in lower premiums for low-risk drivers (Baecke and Bocca 2017). This may also involve business model innovation, from paying a monthly premium to usagebased 'pay-as-you-drive' (Desyllas and Sako 2013). Furthermore, by using digital technology for automation and reducing transaction costs, insurance products can expand to low-severity risks and short time-span coverage (i.e. on-demand) (Eling and Lehmann 2018). While technology makes insurance more inclusive in this way, it may also result in excluding high-risk cases (The Geneva Association 2018). In addition, because of better prediction models, insurers can shift "from loss compensation to loss prediction and prevention" (Eling 2021, p.1). While insurance products in general would not become completely redundant as liabilities shift, risk prevention would benefit economic welfare in general (Eling and Lehmann 2018). Finally, there is a recent trend towards offering bundles of complementary products and services involving actors from different industries. In keeping with this trend, 
Fritzsche and Bohnert (2021) argue that insurance providers can leverage their core competence related to risk management and offer a comprehensive service that encompasses different domains.

\section{Ecosystem}

A third key insurance dimension in which digitalisation has been important is related to the channel through which insurers communicate, transact, and distribute their products. Initial academic work in this area focused on the emergence of the internet as a potential information channel, offering advantages such as providing broad information to (potential) customers in a cost-effective and personalised way (Kaiser 2002). Meeting customers where they are by digitalising distribution channels also offers opportunities to obtain additional data from customers and understand customer needs better (Kaiser 2002). However, insurance products are perceived as complex (Mikolon et al. 2015), which may well hinder the full digitalisation of the customer journey by removing human advisory interaction altogether (De Keyser et al. 2019). Therefore, the disintermediation effect of the internet has been limited in some insurance markets (Garven 2002). Moreover, due to lowered entry barriers, the internet has led to the introduction of new intermediaries (Garven 2002). As to after-sales service, the internet can be used to improve the customer experience and reduce the cost related to claims management (Gebert-Persson et al. 2019).

Additional technologies have been identified for digitalising the channel (Eling and Lehmann 2018): mobile applications, chatbots, robo-advisors, social media, and video-conferencing. These technologies can be used to further improve customer acquisition, experience and service. For instance, insurers can offer mobile apps to file claims immediately, and deploy robo-advisors to support or replace human advisors (De Keyser et al. 2019; Eling and Lehmann 2018; Eling 2021). Consistent with the trend toward complimentary bundles of products and services, insurance distribution channels are evolving into ecosystems that not only include vertical channel partners but also a network of mutually dependent institutions from different sectors (Fritzsche and Bohnert 2021; Jacobides 2019). Insurance providers face an important strategic decision in this matter, as they may disappear in the background and become dependent on others' offerings or instead increase their reach and presence by taking the lead in the ecosystem (Fritzsche and Bohnert 2021).

\section{Impact of digitalisation}

In a study that adopts a broad perspective on digitalisation in insurance, Bohnert et al. (2019) argue that socio-economic trends, such as digital transformation, impact the insurance business both in terms of internal activities (e.g. business operations, management, control) and external activities (i.e. connections with customers and partners). Based on text mining analysis of the annual reports of European insurance companies over a decade, the authors found that expressing a digital agenda was positively related to firm performance. Moreover, they found that when insurers focused their digitalisation efforts on both internal and external activities, they 
enjoyed the highest impact (Bohnert et al. 2019). Similarly, based on a systematic analysis of prior work on digitalisation and a discussion of potential applications of digital technologies across the insurance value chain, Eling and Lehmann (2018) identified four areas to study the impact of digitalisation: enhancing the customer experience, improving business processes, offering new products, and preparing for competition with other industries.

\section{Research approach}

Because of the exploratory, complex, and emerging nature of the open insurance phenomenon, we have complemented our literature review with a qualitative research method (Yin 2014) involving desk research and semi-structured interviews with industry experts. Through purposeful sampling (Patton 2002), we have selected key informants in Europe. The European insurance industry is mature with a stable operational infrastructure (Bohnert et al. 2019). Therefore, the concept of open insurance may be particularly challenging from a technical perspective. In total, 30 interviews were conducted with experts from different types of organisations involved in the insurance industry (see Appendix 1): insurance and bank-insurance companies, insurance intermediaries (banks and brokers), Big Tech, FinTech, InsurTech, regulators, consultants, and other financial services companies. To stimulate participation, the experts were promised a feedback report.

As to the selection of the experts, we identified key informants (Bagozzi et al. 1991) with specialised knowledge on the subject matter of open insurance. Key informants tend to not report personal feelings or opinions, but provide input at a higher level of abstraction (Campbell 1955), which decreases the likelihood of biased or socially desirable responses. Also, given the strategic sensitivity of the subject, we offered the interviewees the possibility to remove sensitive content from their interview transcripts and promised to only quote them anonymously (Gioia et al. 2013).

As to the data collection instrument, the interview guide was developed and structured based on the literature review and focused on the research questions. The guide consisted of 12 open-ended questions (see Appendix 2), most of which were generic to all stakeholder groups, while some questions were specific to the respondent category. ${ }^{6}$ To avoid confirmation bias, we asked the questions in an open, nonleading way and refrained from providing our definitions or sharing our thoughts (Gioia et al. 2013). Also, we ended each interview by asking "Is there anything we forgot to ask or any information you would still like to add?" to ensure we had covered all the relevant topics.

Each interview took about one hour and was recorded, transcribed, and validated with the respondent. Each interview transcript was then analysed in full through

\footnotetext{
${ }^{6}$ For instance, when interviewing experts from bank-insurers we also asked about open banking initiatives; when interviewing regulators, we also asked for details about the process of obtaining a third-party license; and when interviewing Big Tech we also asked about their strategy beyond Europe.
} 
selective coding, which involved organising the concepts and dimensions in alignment with the research questions and literature review (Patton 2002). In particular, the interview data was coded to distinguish antecedents, dimensions, and outcomes of open insurance strategy. Moreover, the data was organised in terms of different types of drivers, three levels of openness within each dimension (i.e. data, products, ecosystems), and different categories of performance impact. To increase the validity and reliability of the coding outcomes, the different concepts and their interrelationships were shared with the respondents and their feedback was incorporated in the analysis. Through this approach, we could clarify ambiguities and organise the findings to answer the three research questions.

\section{Findings}

\section{Definition of open insurance}

Consistent with our definition in the literature review section, the experts identified data and data exchange as the key differentiator relative to 'closed' insurance, referring to "data access without much barrier." A consultant specified the potential added value of exchanging data for process enhancements such as "profiling customers and better assessing the risks." Others referred to potential new revenue streams for insurers "by leveraging data because financial companies have a treasure of information on clients." Furthermore, the experts referred to the presence of third parties, which can expand the product offering. According to one of the experts, open insurance is "enabling third parties to develop new insurance value propositions" and another expert referred to "core insurance functionalities [that] can be accessed by virtually any party or developer to build on that." Regarding the distribution channel, one expert referred to "moving away from classic distribution... to insurance embedded in a context" and another talked about "plugging insurance super-easily in any ecosystem."

\section{Drivers of open insurance}

Based on our research, three main sets of drivers of open insurance were identified, namely regulation and standards, market, and digital technology (as summarised in Table 1).

While all experts agreed that regulation, in particular PSD2, had played an important role in stimulating open banking, it was not considered the main driver for open insurance given that insurance was not within its scope. However, a relevant legislation that did apply to insurance, as it did for all companies active in the European Economic Area, was the GDPR. The experts were expecting the European regulation related to protecting customer data and stimulating market competition to 
Table 1 Drivers of open insurance

\section{Regulation and standards}

Market

Customers

Assets of incumbent insurers

Technology players offering insurance products

Digital technology
Regulation with a direct impact (cf. PSD2)

Regulation with an indirect impact (e.g., GDPR)

Imposed or voluntary standards (e.g., OPIN)

\section{Customer-centricity}

Transparency

Integrated experience

Personalisation and customisability

Positive: trust, experience, financial resources, and data Negative: legacy IT and distribution systems

InsurTech

Big Tech

API

AI, IoT, cloud, blockchain

indirectly impact the insurance sector. ${ }^{7}$ A consultant reported: "There is already regulation related to data and data sharing and the EU is further working on let's say their data strategy. This regulation will further evolve around how data is being shared and how it is governed."

In addition to such regulation that indirectly impacted the insurance industry, there was an expectation among the experts that regulation directly targeting insurance would arrive soon. The interviewees referred to a proposal on regulating data access in open finance that the European Commission was developing by mid2022. An InsurTech representative applauded the standardisation and interoperability this is expected to bring: "There needs to be a harmonization on the European level on all those small technical rules that everybody has put in place that hamper innovation and forces everybody to stay in their own markets." A representative of an insurer noted another important factor in terms of licensing third parties: "At the moment, we spend huge time and efforts to authenticate third parties that want access to our data, it would be very helpful for us, and the insurance industry in general, if a regulator could centralize this process."

The experts also pointed out that in anticipation of imposed standards, many players in the industry were seeking to join voluntary open insurance initiatives with the goal of establishing API and data portability standards. For example, 61 companies around the world were involved in the Open Insurance Initiative Network (OPIN). ${ }^{8}$ Other notable initiatives included Open Cologne, Insurance of the Future Initiative,

\footnotetext{
7 See for instance upcoming regulation on human-centric AI by the European Commission (https://digit al-strategy.ec.europa.eu/en/library/communication-building-trust-human-centric-artificial-intelligence).

8 For more information, see https://openinsurance.io/.
} 
and Free Insurance Data Initiative. It is also of interest to note that more broadly, various initiatives were emerging for establishing open finance standards. ${ }^{9}$

The second driver is the market, for which it is important to distinguish the role of many different players in open insurance: customers, incumbent insurers, banks, intermediaries, FinTechs, Insurtechs and Big Tech. As to the customers, the experts referred to a need for more proximity, a closer relationship, and more touch points, and a banker commented: "You cannot build a relation with somebody you never meet or you only need once a year." Open insurance would be an opportunity to rethink insurance from a customer-centric perspective. As a regulator reported: "I could personally see the potential for strengthening the relationship between the provider and the consumer... I think open insurance can simplify the process, make it more digital and accessible and understandable for consumers." In addition to transparency, the experts indicated that customers were asking for an integrated experience, personalisation, and customisability in insurance.

The experts generally did not consider the incumbent insurers to be promoting open insurance. Some expert comments were as follows: "the traditional players are still sitting comfortably in their chairs" and "they're sleeping, don't wake them up..." Furthermore, the existing distribution channels and legacy IT systems were identified as factors that inhibited insurers to lead the move to open insurance. Nevertheless, the experts indicated that incumbents did have advantages that should protect them from becoming redundant: trust, experience, financial resources, and data. As to the latter, one expert questioned the accuracy of the data insurers have: "most likely the data which is outside is more accurate than the data which is inside the insurance company." Indeed, incumbent banks seem to have already made important progress towards open banking and what is happening in banking is regarded as a driver for insurance as well. Next, incumbent intermediaries (i.e. brokers and agents) are perceived as having a lot of power due to their physical presence and proximity to the customer in some markets, ${ }^{10}$ but are not necessarily using that power to move towards open insurance.

The experts recognised that the transition to open insurance was heavily fueled by FinTechs (InsurTechs in particular) and Big Tech companies. InsurTechs were considered as potential partners, both for incumbent insurers and intermediaries, as one expert commented: "InsurTechs and the insurers have realized that collaborating is much more profitable and much more effective than competing with each other." Indeed their assets were perceived as complementary: incumbent insurers had the financial resources and customer base, whereas InsurTechs worked with the latest technology and acted flexibly. Big Tech, however, was labelled more as a direct threat to incumbent insurers, as one expert commented: "They will definitely drive the real change [that] insurance companies will be forced to go with." The reasons mentioned by the experts include Big Tech's technology prowess, large user bases, and significant financial resources. On the contrary, relatively limited returns and

\footnotetext{
9 An example is the Berlin Group Open Finance API Taskforce, see https://www.berlin-group.org/openfinance

10 Belgium is an example, see Muylle et al. (2018).
} 
potential customer conflicts with selling cloud services may inhibit Big Tech from entering the insurance market directly, as per the interviewees. Finally, experts from incumbent insurance providers were adamant that to level the playing field, data reciprocity was a key principle, meaning that if they need to open up and share data with Big Tech, data exchange should also happen in the opposite direction.

A third and final driver of an open insurance strategy is technology. The opinions and ideas shared by the experts were in line with our literature review: APIs are considered the key enabling technology. A bank representative indicated: "We are moving to an API Economy, APIs will change the world. At the moment, the financial services are in fact a little bit ahead of other industries in that sense." Another interviewee added: "In the digital economy, companies are loosely connected. Joint ventures or strategic partnerships are too rigid, but APIs can support the required scale and automation." The experts indicated that another key technology was AI, as an interviewee commented: "Of course AI is important, because open insurance is about data and so what you do with that data is often applying AI. But while there are many use cases for AI in insurance, it is not the core of open insurance itself." Additional important technologies that were mentioned include cloud, IoT, and blockchain.

\section{Open insurance framework: dimensions and levels of openness}

In this section, we present an open insurance framework (see Fig. 1). Consistent with the literature review, the framework has three dimensions (data, product, and ecosystem) and three levels of openness (more closed at the bottom and more open at the top). In other words, at the lowest level (or most closed level), insurance providers conduct underwriting, pricing, and claims processing based on proprietary data, and offer insurance products through established insurer channels. In what follows, we use quotes provided by the experts and examples from our literature review to explain and illustrate how each dimension can be opened up in turn.

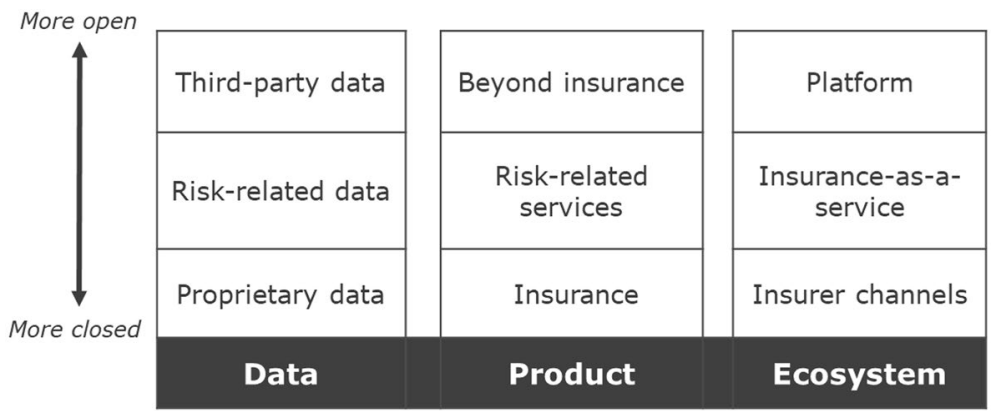

Fig. 1 Framework for open insurance strategy 
Table 2 Examples of opening the data dimension

\begin{tabular}{ll}
\hline Data level & Examples \\
\hline Proprietary data & $\begin{array}{l}\text { AXA_Give data back: on an AXA-branded website, visitors can find an estimate of } \\
\text { risks and claims related to theft, water damage and fire for a specific region, based } \\
\text { on anonymous, aggregated data from its customer base }\end{array}$ \\
Risk-related data & $\begin{array}{l}\text { Discovery_-Vitality: The Vitality programme involves partnerships with various } \\
\text { medical insurance companies around the world. For customers, the process starts } \\
\text { with a health review (an online survey), based on the analysis of which a score is } \\
\text { produced ('Vitality Age'). Next, the customer can set a goal in terms of physical } \\
\text { activity and connect a wearable to help track progress towards that goal. Customer } \\
\text { are rewarded for healthy lifestyles by earning points that can be redeemed for gifts } \\
\text { Admiral-Facebook data: For young drivers that want to obtain car insurance for } \\
\text { the first time, there is no historical data. They are usually considered as high risk. } \\
\text { Admiral allowed these young drivers to share their Facebook data (e.g. who are } \\
\text { they connected to and what kind of content do they post) through an application } \\
\text { (this was before Cambridge Analytica), such that the insurer could establish a rela- } \\
\text { tionship between such social media data and driving behaviour (and the associated } \\
\text { risks) }\end{array}$ \\
\end{tabular}

\section{Data}

As to the Data dimension, an insurance provider can move from processing proprietary (risk) data, over gathering and using risk-related data, to accessing and leveraging third-party and public data (see examples in Table 2).

At the first level, data is wholly owned (sourced and stored) and processed (analysed) by the insurer. The insurer can choose to open this proprietary data to third parties, typically through APIs. According to one interviewee: "How can we use data as an asset and unlock it to organizations that have the capability to develop new, relevant value propositions out of it?" A representative of an InsurTech added: "The access to risk data is extremely valuable. Who has the most data in the insurance industry? The re-insurers! ... Data is at the core of the reinsurance model." While some examples of opening historical data (publicly) have emerged, the matter of monetising data remains a stumbling block, according to the experts. Another use case concerns insurers that recognise the supremacy of third parties (e.g. larger competitors, Big Tech, or InsurTechs) in advanced data analytical techniques (e.g. $\mathrm{AI}$ ), and as a result outsource data management and processing to them. A final case is where customers in Europe ask to obtain access to the data the insurer has about them, which companies need to provide upon request within the GDPR legislation. ${ }^{11}$ The experts indicated they definitely expect corporate customers to be interested in obtaining their own data to in turn incorporate that data in their own internal

11 For more information on GDPR in insurance, see Dexe et al. (2020). 
processing. Also, they pointed to some industry initiatives that supported such data portability. ${ }^{12}$

At the second level, the insurer can opt to add risk-related data. Various technologies that generate data can be considered, such as sensors (as part of the IoT), wearable devices, smart cars, enterprise and web applications, and mobile devices. For instance, an insurer can add a box full of sensors to the car of a customer to analyse driving behaviour and adjust the premium accordingly. Alternatively, sensor data of the customer's mobile phone could be accessed for this application. As another example, an insurer can partner with a wearable device manufacturer and request access to data that provides information on the health profile of the wearer. According to the experts, in combination with AI, processing such data can lead to a shift from loss compensation to risk prediction and prevention.

At the third level, the insurer recognises the value of further augmenting its data collection with data from third parties or with public data. Such data can be financial (e.g. payment data obtained through PSD2) or from other sources (e.g. social media) and can include climate, crime, health, and geospatial data. The difference from the previous level is that the data was not primarily gathered (by the original source) to assess any particular risk to be insured. Therefore, incorporating such data in internal processes and products hinges upon identifying not only a statistical correlation with insured risks, but also establishing a causal explanation.

\section{Product}

Opening the product dimensions refers to insurance providers expanding their offerings and their role in the customer journey, based on an exchange of data (see examples in Table 3).

At the first level, insurance products can be expanded with data related to other (competing) insurance products. This can take the form of dashboards, aggregator and comparison websites that provide an overview of different insurance products. A dashboard could help identify overlap or gaps in customers' risk protection. An aggregator application or comparison website additionally allows easy comparison of the coverage/price ratio (potentially based on common indicators) and selection of the best option. An interviewee commented: "There are some insurance aggregators on the market and the potential value is high. However, all insurance policies have a different format, because there is no regulatory framework. Hence, integrating different policies in one place is a nightmare!" Another use case that is considered at this level is on-demand insurance. This can be considered a disaggregation of the insurance product over time, based on data provided by the customer or leveraging data-based automation.

At the second level, insurers further expand their product portfolio with other services directly related to insured risks ('risk-related services'). Except for life insurance, insurance products usually play a secondary, supporting role in the customer

\footnotetext{
12 For an example in Germany, see http://www.friendsurance.com/wp-content/uploads/2020/01/Frien dsurance-Press-Release-FRIDA-20200107-English.pdf.
} 
Table 3 Examples of opening the product dimension

\begin{tabular}{ll}
\hline Product level & Examples \\
\hline Insurance & Public comparison websites: In several European countries (e.g. Estonia, Italy, \\
Latvia, Norway), public comparison websites are established for motor insur- \\
ance, which is required by law. These websites use consumer data (e.g. ID \\
card or license plate) to provide specific quotes. Insurers also integrate with \\
the website (required by law), such that their systems can be accessed (through \\
APIs). Insurance intermediaries can also use this website to provide advice to \\
customers \\
AXA-Doctors Online: AXA expanded its hospitalisation insurance plan with \\
a free service to consult a medical doctor online, any time of the day or week, \\
regardless of the customer's location (local or abroad). An AXA customer can \\
schedule an appointment online and engage in a telehealth session with an \\
independent medical doctor. AXA is not in itself a health institution or pro- \\
vider of medical services but merely organises and facilitates teleconsultations \\
between its customers and independent physicians. The customer provides \\
consent to process his or her health data for teleconsultation through the AXA \\
e-Health platform \\
AG Insurance-SoSimply: In this new offering, AG Insurance leverages its \\
network of over 400 professionals (e.g. plumbers, electricians, locksmiths, \\
painters) to serve anyone that is looking for a professional to refurbish their \\
homes. AG Insurance customers and non-customers alike can use the SoSim- \\
ply web form (and attach pictures) or call SoSimply to describe their project, \\
and SoSimply then identifies and qualifies a professional, offers a quotation, \\
and guarantees cycle time and the quality of the work. SoSimply involves \\
APIs to exchange operational data with some large repair firms for efficiency \\
purposes. After completion of the works by the professional, SoSimply \\
ensures its customer is satisfied and sends the invoice
\end{tabular}

journey. For instance, a customer buys a house or car and as a corollary wants (or is legally obliged) to insure that property. Providing travel insurance to customers when they go on vacation is another case in point: the customer is not actively looking for an insurance, but only comes to think of it, or is made aware of it by the insurer, when going on vacation. According to the experts, insurance providers can strategically choose in which customer journeys they want to play a more prominent role and establish data exchanges with relevant complementary parties. Some journeys that were identified as likely candidates by the experts relate to mobility, housing, and health. For instance, car insurance can be extended with a service to repair the car in case of damage, with a tool to purchase secondhand cars of which they know the (accident) history, or with car-sharing services. One expert noted: "You can tell when insurers go this route when you see them doing more advertising, in order to develop their brand and recognition in an area." At the same time, the experts also expected the opposite trend, namely insurance providers that increasingly outsource a part of the journey, for instance claims management, by exchanging data with the third party through APIs. 
At the third level, insurance providers can further expand beyond insurance and risk-related services and offer a complete solution for a need in a customer-centric way. They can become a 'partner in life' by centralising relevant data to offer a single touch point and supporting the end-to-end customer journey. As the insurance product now plays a small part or becomes negligible in the solution, this level is referred to as going 'beyond insurance'. The experts warned that insurers that take this route need to adapt their organisation accordingly as it significantly increases the communication frequency and relationship level with customers. Namely, the insurer-customer interaction extends beyond initial purchase and claims filing and becomes continuous.

\section{Ecosystem}

The Ecosystem can be opened up from the level of the insurer's existing channels, over integrating insurance products into others' channels (insurance-as-a-service or embedded insurance), to establishing a platform strategy (see examples in Table 4).

As to the first level, insurance providers can augment their channel by opening up and partnering for improved customer interaction. For instance, third parties may provide a chat tool to strengthen the website or social media presence of an insurer or intermediary. These third parties can assist customer acquisition and customer service by tapping into both the data of the insurer and third-party (aggregated) data they have access to. Likewise, insurers may leverage partnerships that help to identify and communicate cross- and up-selling opportunities, based on a combination of data sources. Another use case is third parties that help insurers with using their own channels to acquire more data in a regulatory-compliant way.

As to the second level, this is where insurance becomes part of third parties' customer journeys. More broadly, insurers can create APIs and make them available to

Table 4 Examples of opening the ecosystem dimension

\begin{tabular}{|c|c|}
\hline Ecosystem level & Examples \\
\hline Insurance channels & $\begin{array}{l}\text { WeGroup is an InsurTech that offers its services to insurance intermediaries in } \\
\text { multiple European countries. A virtual assistant that can be accessed through } \\
\text { the intermediary's website or that responds to email, automates customer } \\
\text { interaction for marketing purposes and claims management. The assistant } \\
\text { understands several languages and responds accordingly }\end{array}$ \\
\hline Insurance-as-a-service & $\begin{array}{l}\text { Tesla Insurance: While Tesla sells cars and mobility services through its own } \\
\text { channels and mobility platform, and leverages its operational data from the } \\
\text { sensors and cameras in its products, it also develops an ecosystem around } \\
\text { its connected car by enlisting insurers. Tesla insurance underwriters differ } \\
\text { depending on geography. In British Columbia, Canada, for instance, the } \\
\text { InsureMyTesla programme is administered by Aviva Agency Services Inc., } \\
\text { who distributes insurance products underwritten by S\&Y Insurance Company } \\
\text { and Traders General Insurance Company }\end{array}$ \\
\hline Platform & $\begin{array}{l}\text { KBC Group, a Belgian bank-insurer, offers services and applications of over } 50 \\
\text { external providers for mobility, entertainment, and other services through its } \\
\text { mobile app }\end{array}$ \\
\hline
\end{tabular}


third parties such that the latter can use them to develop new services, applications, and value propositions. The insurance product can be added white-labelled (without the insurer's brand) or with visibility for the brand. This level is referred to as 'Insurance-as-a-Service' or as 'embedded insurance'. An interviewee from an insurer explained the ways in which these partnerships can come about: "Sometimes we push for a partnership and sometimes we are asked. For instance, car manufacturers usually come to us and ask to sell our insurance products, while taking a margin on the transaction." The experts agreed that financial services will move to the background in some areas for some customers, but an interviewee commented: "There will always be customers and companies with complex financial needs, there will always be a need for specific advice, so financial services will never be completely in the background."

As to the third level, insurers can develop a digital platform through which customers can orchestrate all or most of their (digital) activities. An example of such a platform is WeChat, the so-called 'everything app' from Tencent, which started as a messaging app, and branched out to gaming, banking, health, and so on, and now also offers a broad range of insurances to its users, as they organise their lives on this platform. According to the experts, this position is strategically challenging for insurance companies, due to their infrequent interaction with customers. Instead, banks were considered to be more likely to assume this position. An interviewee commented: "I don't know whether we should be the platform because I'm not sure we would be good at doing that and whether we are naturally acceptable for the customer as a platform." Another expert pointed out differences across customers and their associations with financial services: "Some customers might be interested in accessing seemingly unrelated services via the platform of a financial service provider, as they visit the application anyway. What's required is an analysis of the type of services are associated with each other, across customer segments."

It is important to note that while each of the dimensions can be explored independently, strong synergies are possible by combining them. For instance, on-demand insurance (first level of the product dimension) can be triggered by processing by an insurer of third-party data (third level of the data dimension): based on location data of customers or based on integration with their calendars, an insurer could discern customers are travelling and send them a push notification for luggage insurance for the duration of the travel. Another example concerns insurance aggregation (product dimension) based on payment data (data dimension) retrieved based on PSD2driven API integration. Other data that can be captured from payments may relate to key life events, such as buying a house or giving birth to a child, which in turn triggers contact opportunities for insurance conversations. Also, risk-related data captured from sensors (second level of the data dimension) may be used to offer tailored advice, for instance on driving style (second level of the product dimension). As to combining the data and ecosystem dimension, new capabilities can be added to existing channels such as emails or websites (first level of the ecosystem dimension), based on third-party or public data (third level of the data dimension). For instance, based on location data of a potential customer, a maps application can be consulted to sense whether there are solar panels and/or a swimming pool at this location. If 
that is the case, the conversation with the potential customer can be about insuring certain related risks.

\section{Impact of open insurance strategy}

The experts' opinions varied widely concerning the relevant time horizon for seeing the impact of open insurance initiatives. The sensitivity of risk data is widely regarded as a complicating factor, because establishing ethics and norms on exchanging such data takes a lot of time. Moreover, some of the experts indicated that powerful insurers are trying to impede progress towards open insurance, for instance through lobbying against standards for data exchange. Moreover, an interviewee commented: "Everybody wants to obtain the data of the others, but no one wants to share their own data..." However, there was consensus on potential accelerators, namely regulation and the entrance of Big Tech, as illustrated by the following quotes: "In five years from now, it will still be in the innovation phase...It will depend also on the regulation or an external player that really has the skills to leverage scale, like we saw with Amazon in retail."; "I believe there is a lot of inertia in insurance. So I see a cycle of 25 years honestly... It might be a different story, however, if one of the BigTechs enters a certain space very aggressively."

The experts identified two categories of performance impact related to open insurance: enhanced operational efficiencies and novel customer experiences based on an expansion of products and channels. The efficiency gains can be mostly related to data processing, as a better use of more data was expected to lead to faster process cycle times, potentially enhancing the accuracy of risk underwriting and reducing the occurrence and cost of claims. A positive side effect observed by some experts was that large European insurers had better coordination and communication across the countries in which they operated thanks to their open insurance initiatives. However, in keeping with Porter (2001), operational efficiency improvements do not provide a sustainable competitive advantage. Given that the barriers to imitation are low, open insurance would simply raise the table stakes for everyone in the industry.

Improved customer experiences are mainly related to opening up the product and ecosystem dimensions, as one expert commented: "In the end, customers will be the big winners because an integrated experience will be built around them for each product." Such initiatives were motivated by insurers that were seeking new revenue streams, but while many examples had started to emerge (see Tables 3 and 4), it was not clear yet which ones would become successful. Even though providing embedded insurance was seen as commoditising insurance and putting pressure on margins, the experts believed this was preferred over being completely absent in the customer journey. While in the short run, especially without regulation, the impact might still be marginal, some experts expected open insurance to be a potential game changer for the customer experience, especially regarding the number and frequency of insurer-customer interaction touch points. Additional advantages of open insurance for customers include the ability to easily compare and switch providers and to obtain truly personalised services.

For third parties, including intermediaries, Big Tech, and InsurTech, potential benefits of open insurance include offering tailored products and pricing to their own 
customer base and potentially that of the insurer. Such offerings can be based on a fine-grained assessment of risk and more efficient interaction and compliance processes, especially if it is based on standards for data exchange with insurers. Given that incumbent insurers often lack the capabilities necessary to seize open insurance opportunities, partnerships with InsurTechs and Big Tech gain in importance and become a source of competitive advantage in insurance. Some experts cautioned though that if insurers were investing in InsurTech, it was hard for the latter to remain impartial, as one interviewee commented: "This is very counter-intuitive: as long as incumbents invest in InsurTechs and try to influence them, there will never be a fully open insurance landscape." While InsurTechs were seen as partners that did not pose a threat by the experts, this is different for Big Tech. Indeed, it is important to note that Big Tech companies can come in from the top row of the framework (third-party data, beyond insurance, platform) and deepen their involvement in insurance as they seek opportunities to offer insurance to their huge user bases.

Also, an important debate in open insurance is who assumes the role of data custodian? Without data reciprocity (i.e. incumbents also have the right to access data of digital players), there is a risk of Big Tech taking over the custody and governance of user data beyond their traditional activities. While financial service providers do enjoy the trust of their customers, ${ }^{13}$ they need to strike a balance in leveraging the customer data. A related threat was losing the customer interface and the commoditisation of insurance, with insurance products increasingly expected to become embedded in other products. In a next phase, tech players could also start carrying the risk that is typically covered by insurance companies. For instance, Tesla announced that it plans to become a fully-fledged insurer in time, as it leverages its product data, and hence could potentially drop its current insurance partners. ${ }^{14}$ In addition, due to expectations of standardisation and platform network effects, there was a fear among the experts of winner-take-all or -most mechanisms, in which Big Tech could dominate specific risk product categories.

\section{Conclusion}

While open insurance is currently a buzzword in the insurance industry, the topic is still scarcely researched. Open refers to data exchange between insurers and third parties and may profoundly impact the insurance landscape. Indeed, the insurance industry ranks among the highest in Accenture's Disruptability Index, due to eroding entry barriers and incumbents' competitive advantages (Abbosh et al. 2019). This transformation is multi-dimensional and difficult for incumbents to navigate when in the midst of it (Kane et al. 2017). To be successful and avoid disruption, it

\footnotetext{
${ }^{13}$ For a recent study on trust of financial service providers and Big Tech, see https://www.businessin sider.com/digital-banking-users-name-primary-fis-as-most-trusted-provider-2021-6 (accessed on 11 June 2021).

14 For more information, see https://www.businessinsider.nl/elon-musk-tesla-launching-insurance-compa ny-nationwide-hiring-2020-7 (accessed on 11 June 2021).
} 
is important for insurance companies to have strategic insight and foresight on the industry shift and pivot by implementing adequate innovations.

Based on a literature review and interviews with 30 insurance industry experts, we have developed a definition and provided an answer to three key research questions. As to the first question, we identified and discussed three categories of drivers of open insurance: regulation and standards, the market, and technology. As to the second question, we developed a framework for open insurance strategy that is in keeping with prior research, as we consider multiple dimensions (Eling and Lehmann 2018) and both internal and external activities (Bohnert et al. 2019). Finally, we uncovered the different ways in which open insurance may impact the insurance industry. The framework developed in this paper is meant to help practitioners better understand open insurance and assist them in jockeying for position, in anticipation of regulation to come into effect.

As to the validity and reliability of our research approach, the way in which the interviews were conducted was influenced by the COVID-19 pandemic. Before the pandemic, most of the interviews were conducted face-to-face. Conversely, during the pandemic, the interviews were conducted using video-conferencing technology. While it is harder to build a rapport in video-conferences vis-à-vis face-to-face meetings (Standaert et al. 2021), video interviews are valid and reliable alternatives when in-person interviews are not possible, serving the "purpose in a more costeffective way while promoting inclusion and equality in research" (Saarijärvi and Bratt 2021, 396). Therefore, we do not expect our findings to be influenced by the interview modality.

As to the generalisability of our findings, it is important to note that while we have interviewed multiple informants from different stakeholder groups until we were reaching theoretical saturation in the analysis (Eisenhardt 1989), it is still possible that other experts would have provided additional insight. Moreover, given our key informant approach, it is also likely that the maturity level for open insurance at the companies they represent is higher than the industry average. So while the insights may not be generalisable at the time of this study, we expect them to be indicative of where the industry is heading.

We hope this study can motivate academics to further explore open insurance. Because of the emerging, broad, and complex nature of the topic, we have adopted a qualitative approach. However, a larger scale quantitative study could examine to what extent the three drivers of open insurance are experienced differently, for instance across insurance product categories or across time. Also, future research could broaden the geographical scope of researching open insurance strategy, similar to the open banking context, as the drivers could differ especially. ${ }^{15}$ Moreover, an instrument could be developed based on our framework with the three dimensions to assess the different levels of openness of real-life insurance offerings. The resulting patterns would allow the relationships (correlations of openness) across the dimensions to be more closely examined. Furthermore, while insurance companies

\footnotetext{
15 See Deloitte's report at: https://www2.deloitte.com/tw/en/pages/financial-services/articles/open-banki ng-around-the-world.html (accessed 29 October 2021).
} 
are historically advised to focus on data defence strategies (i.e. minimising risk and downside by ensuring compliance, security, privacy, data quality and integrity) because of regulatory requirements, our research and framework revealed that, currently, the focus in open insurance is on data offence strategies (e.g. supporting business objectives, such as creating customer experiences, generating insights, and maximising value) (DalleMule and Davenport 2017). Finally, there is an opportunity to validate the relationship between openness and performance in an objective way. In keeping with Bohnert et al. (2019), such analysis could be based on text mining of the annual reports of European insurers.

\section{Appendices}

\section{Appendix 1: Interviewees}

Insurance companies:

- Frederic Dhallewin, Head Partnership Development, AG Insurance

- Steve Goossens, Director Digital Office, P\&V/VIVIUM

- Edwin Klaps, Managing Director Broker Channel \& Non-Life Development, AG Insurance

- Sudaman Thoppan Mohanchandralal, Chief Data Officer, Allianz

- Robert Ter Weijden, former Head of Strategy and Business Development, Ageas

- Gunter Uytterhoeven, Chief Customer/Data/Sustainability Officer, AXA Belgium

Bank(-insurers):

- Benoît Speybrouck, Director Digital Programs, Belfius

- Bart Verbeek, General Manager Strategy \& Organisation BU, KBC

Banks and brokers:

- Koen Adolfs, Product Owner Open Banking, ABN AMRO

- Wouter Bartels, Director Transaction Banking Channels \& Open Banking, ABN AMRO

- Johan Kestens, former CIO, ING Belgium

- Kelly Schamphelaere, CEO, Federatie voor Verzekerings (FvF)

- Izzy van Aelst, Director Customer Insights, BNP Paribas Fortis

- Maarten Verboven, Director Open Banking, BNP Paribas Fortis

Big Tech:

- Paul Rohan, Head of Business Strategy — Finance, Google

FinTech: 
- Arvid De Coster, CEO \& Co-Founder, WeGroup

- Steven Geclowicz, Country Manager Belgium, Revolut

- Matthieu Remy, CEO, easyvest

- Jean-Charles Velge, Co-Founder, Qover

Regulators:

- Andres Lehmets, Expert on InsurTech, European Insurance and Occupational Pensions Authority (EIOPA)

- Frederic Romont, Senior Expert Banking Supervision, NBB

- Reinout Temmerman, Payments \& PSD2 Expert, NBB

- Marjan Wauters, Economist, FSMA

Consultants:

- Charles de Froidmont, Accenture

- Pieter Herremans, Director Insurance, KPMG

- Dave Remue, Director and Fintech Lead, KPMG

Other players in financial services:

- Kris Claessens, CTO, thewave

- Henri Dewaerheijd, General Manager Belgium \& Luxembourg, Mastercard

- Michael Oliva, Director Franchise Management, Mastercard

- Stephan Podevyn, CEO \& Co-Founder, thewave

\section{Appendix 2: Interview guide}

- How would you define open insurance?

- What do you see as the main drivers for open insurance?

- Do you foresee regulator involvement in the future, like what we have seen in the banking sector?

- Do you see open insurance being driven by market shifts?

- Which digital technologies are enabling open insurance?

- What would be an effective open insurance strategy for an incumbent insurer?

- How does open insurance impact data acquisition, analysis, and sharing for insurers?

- What novel products will open insurance offer customers?

- Is open insurance challenging traditional channels for bringing insurance to market?

- What impact do you expect from open insurance? 
- What impact do you think open insurance will have on the insurer-customer relationship?

- How do you view the entry into insurance by new players?

- Is there anything we forgot to ask or any information you would still like to add?

Acknowledgements The first author started working on this research study while at Vlerick Business School. The authors would like to thank the reviewers for their valuable comments, the experts for sharing their personal opinions and insights, and Dr. Hamzeh Obeid for his support with the interviews."

\section{Declarations}

Conflict of interest On behalf of both authors, the corresponding author states that there is no conflict of interest.

\section{References}

Abbosh, O., P. Nunes, V. Savic, and M. Moore. 2019. Breaking through disruption. Accenture 66: 26-30. Baecke, P., and L. Bocca. 2017. The value of vehicle telematics data in insurance risk selection processes. Decision Support Systems 98: 69-79. https://doi.org/10.1016/j.dss.2017.04.009.

Bagozzi, R.P., Y. Yi, and L.W. Phillips. 1991. Assessing construct validity in organizational research. Administrative Science Quarterly 36 (3): 421-458.

Barua, C., B. Gati, T. Lajumoke, Z. Taraporevala, A. Havas, and M. Radnai. 2019. Beyond banking: How banks can use ecosystems to win in the SME market. McKinsey \& Company, pp. 1-13.

Bohnert, A., A. Fritzsche, and S. Gregor. 2019. Digital agendas in the insurance industry: The importance of comprehensive approaches. The Geneva Papers on Risk and Insurance-Issues and Practice 44 (1): 1-19. https://doi.org/10.1057/s41288-018-0109-0.

Campbell, D.T. 1955. The informant in quantitative research. American Journal of Sociology 60 (4): 339-342. https://doi.org/10.2307/2772026.

DalleMule, L., and T.H. Davenport. 2017. What's your data strategy? Harvard Business Review 6: $112-122$.

De Keyser, A., S. Köcher, L. Alkire (née Nasr), C. Verbeeck, and J. Kandampully. 2019. Frontline service technology infusion: Conceptual archetypes and future research directions. Journal of Service Management 30 (1): 156-183. https://doi.org/10.1108/JOSM-03-2018-0082.

Desyllas, P., and M. Sako. 2013. Profiting from business model innovation: Evidence from pay-as-youdrive auto insurance. Research Policy 42 (1): 101-116. https://doi.org/10.1016/j.respol.2012.05.008.

Dexe, J., U. Franke, and A. Rad. 2021. Transparency and insurance professionals: A study of Swedish Insurance Practice Attitudes and Future Development. The Geneva Papers on Risk and InsuranceIssues and Practice. https://doi.org/10.1057/s41288-021-00207-9.

Dexe, J., J. Ledendal, and U. Franke. 2020. An empirical investigation of the right to explanation under GDPR in insurance. In International Conference on Trust and Privacy in Digital Business, pp. 12539. https://doi.org/10.1007/978-3-030-58986-8_9

EIOPA. 2021. Discussion paper. Open insurance: Accessing and sharing insurance-related data. https:// doi.org/10.2854/013491.

Eisenhardt, K.M. 1989. Building theories from case study research. The Academy of Management Review 14 (4): 532-550.

Eling, M., and M. Lehmann. 2018. The Impact of digitalization on the insurance value chain and the insurability of risks. The Geneva Papers on Risk and Insurance-Issues and Practice 43 (3): 359396. https://doi.org/10.1057/s41288-017-0073-0. 
Eling, M., D. Nuessle, and J. Staubli. 2021. The Impact of Artificial Intelligence along the Insurance Value Chain and on the Insurability of Risks. The Geneva Papers on Risk and Insurance-Issues and Practice. https://doi.org/10.1057/s41288-020-00201-7.

Fang, K., Y. Jiang, and M. Song. 2016. Customer profitability forecasting using big data analytics: A case study of the insurance industry. Computers and Industrial Engineering 101: 554-564. https://doi. org/10.1016/j.cie.2016.09.011.

Financial Conduct Authority, UK. 2021. Open finance - feedback statement. https://www.gov.uk/gover $\mathrm{nment} /$ news/projects-lay-the-groundwork-for-a-future-of-robolawyers-and-flying-cars.

Fritzsche, A., and A. Bohnert. 2021. Implications of bundled offerings for business development and competitive strategy in digital insurance. The Geneva Papers on Risk and Insurance-Issues and Practice. https://doi.org/10.1057/s41288-021-00244-4.

Garven, J.R. 2002. On the implications of the internet for insurance markets and institutions. Risk Management and Insurance Review 5 (2): 105-116. https://doi.org/10.1111/1098-1616.00014.

Gebert-Persson, S., M. Gidhagen, J.E. Sallis, and H. Lundberg. 2019. Online insurance claims: When more than trust matters. International Journal of Bank Marketing 37 (2): 579-594. https://doi.org/ 10.1108/IJBM-02-2018-0024.

Ghazawneh, A., and O. Henfridsson. 2013. Balancing platform control and external contribution in thirdparty development: The boundary resources model. Information Systems Journal 23 (2): 173-192. https://doi.org/10.1111/j.1365-2575.2012.00406.x.

Gioia, D.A., K.G. Corley, and A.L. Hamilton. 2013. Seeking qualitative rigor in inductive research: Notes on the gioia methodology. Organizational Research Methods 16 (1): 15-31. https://doi.org/10.1177/ 1094428112452151.

Gollier, C. 1997. About the insurability of catastrophic risks. The Geneva Papers on Risk and Insurance-Issues and Practice 22 (2): 177-186. https://doi.org/10.1057/gpp.1997.13.

Gozman, D., J. Hedman, and S. Kasper. 2018. Open banking: Emergent roles, risks \& opportunities. In European Conference on Information Systems.

Grima, S., J. Spiteri, and I. Romānova. 2020. A STEEP framework analysis of the key factors impacting the use of blockchain technology in the insurance industry. The Geneva Papers on Risk and Insurance-Issues and Practice 45 (3): 398-425. https://doi.org/10.1057/s41288-020-00162-x.

Holland, L., P. Stanley, and V. Summerhayes. 2020. Open insurance: Unlocking ecosystem opportunities for tomorrow's insurance industry. Accenture, pp. 1-20.

Jacobides, M.G. 2019. In the ecosystem economy, what's your strategy? Harvard Business Review 97 (5): $128-137$.

Järvinen, R., U. Lehtinen, and I. Vuorinen. 2003. Options of strategic decision making in services. European Journal of Marketing 37 (5/6): 774-795. https://doi.org/10.1108/03090560310465143.

Kaiser, T. 2002. The customer shall lead: E-business solutions for the new insurance industry. The Geneva Papers on Risk and Insurance-Issues and Practice 27 (1): 134-145. https://doi.org/10.1111/14680440.00160 .

Kane, B.G.C., D. Palmer, A. Nguyen Phillips, D. Kiron, and N. Buckley. 2017. Achieving digital maturity. MIT Sloan Management Review, pp. 1-29.

The Geneva Association. 2018. Big Data and Insurance: Implications for innovation, competition and privacy. Authors: Benno Keller, Martin Eling, Hato Schmeiser, Markus Christen and Michele Loi. March

Lanfranchi, D., and L. Grassi. 2021. Examining insurance companies' use of technology for innovation. The Geneva Papers on Risk and Insurance-Issues and Practice. https://doi.org/10.1057/ s41288-021-00258-y.

Maas, P., A. Graf, and C. Bieck. 2008. Trust, transparency and technology: European customers' perspectives on insurance and innovation. IBM Institute for Business Value \& I.VW University of St. Gallen, pp. 1-20.

Mikolon, S., A. Kolberg, T. Haumann, and J. Wieseke. 2015. The complex role of complexity: How service providers can mitigate negative effects of perceived service complexity when selling professional services. Journal of Service Research 18 (4): 513-528. https://doi.org/10.1177/1094670514 568778.

Morvan, A.-S. 2021. A European open finance framework by 2024. SSRN Electronic Journal 65 (9): 4-7. https://doi.org/10.2139/ssrn.3732405.

Mulhall, J., B. de Jong, and I. Weterings. 2017. Data rich, profit poor, Accenture, pp. 1-13. 
Muylle S., A. Basu, W. Standaert, E. Everaert, and W. Decraene. 2018. Digital Innovation in the Belgian Insurance Market. Vlerick Business School \& Accenture Belux Digital 20/20 Chair. https://www. slideshare.net/accenturebelux/digital-innovation-in-the-belgian-insurance-market-86537151?

O'Leary, K., T. Nagle, P. O'Reilly, C. Papadopoulos-Filelis, and M. Dehghani. 2021. The sustainable value of open banking: Insights from an open data lens. In 54th Hawaii International Conference on System Sciences, pp. 5891-5901. https://doi.org/10.24251/hicss.2021.713.

Patton, M.Q. 2002. Qualitative Research and Evaluation Methods, 3rd ed. New York: Sage Publications.

Porter, M.E. 2001. Strategy and the internet. Harvard Business Review. https://doi.org/10.2469/dig.v31. n4.960.

Pousttchi, K., and A. Gleiss. 2019. Surrounded by middlemen - How multi-sided platforms change the insurance industry. Electronic Markets 29 (4): 609-629. https://doi.org/10.1007/ s12525-019-00363-w.

Rai, A. 2020. Explainable AI: From black box to glass box. Journal of the Academy of Marketing Science 48 (1): 137-141. https://doi.org/10.1007/s11747-019-00710-5.

van Rossum, A. 2004. Ethics, governance, trust and customer relations. The Geneva Papers on Risk and Insurance-Issues and Practice 29 (1): 52-55.

van Rossum, A., H. de Castries, and R. Mendelsohn. 2002. The debate on the insurance value chain. The Geneva Papers on Risk and Insurance-Issues and Practice 27 (1): 89-101.

Saarijärvi, M., and E.L. Bratt. 2021. When face-to-face interviews are not possible: Tips and tricks for video, telephone, online chat, and email interviews in qualitative research. European Journal of Cardiovascular Nursing 20 (4): 392-396. https://doi.org/10.1093/eurjcn/zvab038.

Schiro, J.J. 2006. External forces impacting the insurance industry: Threats from regulation. The Geneva Papers on Risk and InsuranceIssues and Practice 31 (1): 25-30. https://doi.org/10.1057/palgrave. gpp.2510064.

Standaert, W., S. Muylle, and A. Basu. 2021. How shall we meet? Understanding the importance of meeting mode capabilities for different meeting objectives. Information \& Management 58 (1): 1-14.

Standaert, W., S. Muylle, and B. Cumps. 2020. Opening the gates: A framework for an open banking strategy. Journal of Digital Banking 4: 2397-3060.

Tennyson, S., and P. Salsas-Forn. 2002. Claims auditing in automobile insurance: Fraud detection and deterrence objectives. The Journal of Risk and Insurance 69 (3): 289-308.

Trichet, J.-C. 2005. Financial stability and the insurance sector. The Geneva Papers on Risk and Insurance-Issues and Practice 30 (1): 65-71. https://doi.org/10.1057/palgrave.gpp.2510021.

Yin, R.K. 2014. Case Study Research: Design and methods, 5th ed. New York: SAGE Publications.

Zachariadis, M., and P. Ozcan. 2017. The API economy and digital transformation in financial services: The case of open banking. SSRN Electronic Journal. https://doi.org/10.2139/ssrn.2975199.

Zetzsche, D.A., D.W. Arner, R.P. Buckley, and R.H. Weber. 2019. The future of data-driven finance and RegTech: Lessons from EU Big Bang II. SSRN Electronic Journal. https://doi.org/10.2139/ssrn. 3359399.

Publisher's Note Springer Nature remains neutral with regard to jurisdictional claims in published maps and institutional affiliations.

\section{About the authors}

Willem Standaert is Assistant Professor at HEC Liège and Visiting Professor at Ghent University. His research interests are in the areas of virtual meetings, digitally-enabled buyer-supplier interactions, and digital innovation in sports and financial services. Willem's academic work has been published in academic journals such as Business Horizons, Electronic Commerce Research and Applications, Information \& Management, Information Systems Frontiers, Information Technology and Management, Journal of the Association for Information Systems, and Psychology \& Marketing. 
Steve Muylle is Professor and Partner at Vlerick Business School and Professor at Ghent University. His research work is on the use of digital technologies in business and has been published in various outlets including IEEE Computer Society Proceedings, Communications of the ACM, Decision Support Systems, Electronic Commerce Research and Applications, Information and Management, Information Technology and Management, and MIT Sloan Management Review. 